\title{
Effect of moving dairy cows at different stages of labor on behavior during parturition
}

\author{
K. L. Proudfoot, ${ }^{*}$ M. B. Jensen,† P. M. H. Heegaard,‡ and M. A. G. von Keyserlingk ${ }^{* 1}$ \\ ${ }^{*}$ Animal Welfare Program, Faculty of Land and Food Systems, University of British Columbia, 2357 Main Mall, Vancouver, V6T 1Z4, Canada \\ †Department of Animal Science, Aarhus University, Blichers Allé 20, PO Box 50, DK-8830 Tjele, Denmark \\ ¥National Veterinary Institute, Technical University of Denmark, Bülowsvej 27, DK-1790 Copenhagen V, Denmark
}

\section{ABSTRACT}

Cows are often moved from a group to an individual maternity pen just before calving. However, it is unclear whether moving cows during labor may alter their behavior or affect the progress of labor. The aim of this study was to determine if moving cows to a maternity pen at different stages of labor would influence calving behavior or the length of the second stage of labor. Seventy-nine multiparous Holstein dairy cows were moved from 1 of 2 group pens to 1 of 10 maternity pens adjacent to each group pen either $3 \mathrm{~d}$ before expected calving date or when one or more behavioral or physical signs of labor were observed. These signs were noted, and were used to retrospectively categorize cows into 1 of 3 movement categories: (1) moved before labor, (2) moved during early stage I labor (signs of suddenly tense and enlarged udder, raised tail or relaxed pelvic ligaments; could also be immediately prelabor), or (3) moved during late stage I labor (signs of viscous, bloody mucus or abdominal contractions; could also be transitioning to stage II labor). Calves were weighed within $12 \mathrm{~h}$ of birth and remained with their dam for $3 \mathrm{~d}$. The length of the second stage of labor (the time between first abdominal contractions to the delivery the calf) and the total time of abdominal contractions, lying time, and number of position changes from standing to lying made by the cow in the hour before calving were recorded. A single blood sample was taken from the jugular vein of cows 3 to $27 \mathrm{~h}$ after calving to determine content of haptoglobin, a marker of systemic inflammation. The effect of movement category on length of the second stage of labor and behavioral variables was tested with ANOVA; category was a fixed effect and calf body weight (BW) and cow parity were covariates. The relationship between haptoglobin and the length of the second stage of labor was tested in a model with time of sampling relative to calving as a covariate. Cows moved during late stage I had the longest labor, but did

Received July 31, 2012.

Accepted November 24, 2012.

${ }^{1}$ Corresponding author: nina@interchange.ubc.ca not have longer contractions compared with cows in the other categories. These same cows spent half as much time lying in the $1 \mathrm{~h}$ before calving compared with cows in the other categories, but did not differ in the number of position changes from standing to lying. We did not have the power to test the effect of movement category on haptoglobin, but cows with longer stage II labor had higher haptoglobin postcalving. Moving cows to a maternity pen during the late part of the first stage of labor caused a delay in the second stage of labor, and this was likely driven by altered lying behavior.

Key words: transition, labor, calving management, parturition

\section{INTRODUCTION}

The transition period around calving is a very sensitive time for dairy cows; cows are at high risk for disease and must cope with several feed and pen changes during this time (see Ingvartsen, 2006 for a review). Great variation exists across farms in management practices during the transition period; management during this time often depends on the size of the farm and the nutritional regimen used on the farm (see Overton and Waldron, 2004, for a description of dry period grouping strategies). As calving approaches, cows are sometimes left to calve in a group pen (although this practice is banned in some countries, such as Denmark; Danish Ministry of Justice Law no. 520, May 26 2010), or they are moved into an individual maternity pen.

Moving cows to individual maternity pens just before calving is still a common practice on many farms, yet a lack of data is available in the literature to determine when cows should be moved to this pen relative to calving. Often this decision is made based on calving signs; cows are moved when calving is imminent. A combination of physical and behavioral cues before and during labor provides a dairy producer some indication of when calving is imminent. These signs occur just before and during the first 2 stages of labor. Labor is traditionally described using 3 stages (described in detail in Noakes et al, 2001; Jackson, 2004; and reviewed by Mainau and Manteca, 2011), although there is no clear stop and 
start to these stages, as they progress gradually. Thus, it is often difficult to determine which stage of labor an animal is in. A high variation in the timing of labor signs also exists; for instance, Jackson (2004) suggests that the first stage can last from 4 to $24 \mathrm{~h}$.

We will briefly describe the stages of labor using signs that are relevant to our study. A first indicator of impending labor is the relaxation of pelvic ligaments, as this reflects the opening of the cervix (Noakes et al, 2001). An engorged udder may also be present at this time, which will gradually enlarge as labor approaches and during labor. The start of the first stage occurs when the cow's cervix begins to dilate and the calf begins moving into position for delivery. Verification of this first stage can only be achieved by palpating the cervix; however, the cow also begins to show changes in behavior during this stage. The cow has myometrial (uterine) contractions and becomes restless (often characterized by an increase in position changes; Huzzey et al., 2005; Miedema et al., 2011; Jensen, 2012), she also begins to pay attention to her stomach (Jensen, 2012), and she increasingly raises her tail while standing (Miedema et al., 2011). The onset of rhythmic abdominal contractions and the release of the amniotic sac are 2 prominent landmarks of the beginning of the second stage of labor (Noakes et al, 2001). During this stage, the cow is often recumbent (Schuenemann et al., 2011), as the forces of the uterine and abdominal contractions help to expel the calf. During the third and final stage of labor, the placenta is released and uterine involution occurs.

These physical and behavioral cues provide a dairy producer some indication that parturition is approaching, but it remains unclear when cows should be moved to a maternity pen relative to these signs. Moving cows to a new pen too close to calving may increase the number of cows calving in unwanted areas (e.g., the freestall in some cases) or may disturb normal calving behaviors and interrupt the progression of labor. The effect of changing pens too close to parturition has not been tested in cows, but Pedersen and Jensen (2008) found that primiparous sows moved to farrowing crates on the day they were due to farrow experienced longer labors and more stillbirths compared with those moved $20 \mathrm{~d}$ earlier. Moving cows to an isolated, individual pen too early before calving may also be detrimental to the cow. Previous work indicates that multiparous cows subjected to even short-term (15 min) complete social isolation increased vocalizations, heart rate, and hypothalamic-pituitary-adrenocortical axis activity (Rushen et al., 1999).

To our knowledge, no research to date has attempted to determine any changes in behavior or disruptions in the progression of labor in cases where cows are rou- tinely moved to a maternity pen during different stages of labor. Thus, the objective of this study was to assess the effect of moving cows at different stages of labor on calving behavior and the progression of labor.

\section{MATERIALS AND METHODS}

\section{Animals, Housing, and Diet}

This study was conducted at the Aarhus University's research facilities in Foulum, Denmark, between September 2011 and February 2012. Cows were cared for according to a protocol approved by the Danish Animal Experiments Inspectorate, Ministry of Justice, Copenhagen, Denmark, and the University of British Columbia's Animal Care Committee (Canadian Council on Animal Care, 1993).

A total of 79 multiparous Danish Holstein dairy cows were used for this study. Before calving, cows were grouped into 1 of 6 blocks of $14.7 \pm 1.5$ (mean \pm SD) cows based on expected calving date. Cows within a block were moved into 1 of 2 group pens (each $9 \times 15$ $\mathrm{m}$ ) approximately $2 \mathrm{wk}$ before the first cow was due to calve. Group pens had deep straw bedding and 12 individual feeding bins (each $0.75 \mathrm{~m}$ wide). Adjacent to each group pen were 10 individual maternity pens (each $3.0 \times 4.5 \mathrm{~m}$ ) also with deep-bedded straw. New bedding was added daily to the group and maternity pens. Bedding was completely changed in the group pen between blocks, and in the maternity pens after each cow was moved to the milking herd. Composition of the group pen was dynamic as cows left the pen to calve, but at least one nonexperimental animal (pregnant cows or heifers) was in the group pen when the last experimental cow of the block calved.

As calving approached, cows were moved into an individual maternity pen. The timing of this movement relative to calving was dependent on treatment (described below). In half of the maternity pens, the sides were made from vertical tubular metal bars: a 3.0-m-wide side separated cows from the group pen and a 4.5-m-wide side separated cows from neighboring individual pens. In the other maternity pens, a plywood barrier was built around the pen so that cows could only see into the group pen through a $1.5-\mathrm{m}-$ wide window. The pen dimensions were the same in all individual pens. This pen treatment was used to test a different hypothesis (Proudfoot et al., 2012); however, to be sure that this pen treatment had no effect on any of our variables, we included pen type as a categorical variable in our first model. In the $1 \mathrm{~h}$ before calving we found no effect of pen type on standing time or standing bouts $(P=0.48$ and 0.70 , respectively), length of abdominal contractions during this same hour $(P=$ 
Table 1. Definition of the signs of calving used to move cows from a group pen to an individual maternity pen

\begin{tabular}{ll}
\hline Sign of calving & Definition \\
\hline Tense and enlarged udder & $\begin{array}{l}\text { The udder is enlarged considerably relative to the previous inspection and is tense. The cow may pay } \\
\text { attention to the udder by turning the head toward it, or by licking it }\end{array}$ \\
$\begin{array}{l}\text { The pelvic ligament near the tail head appears sunken and feels soft and flexible when palpated } \\
\text { Relaxed pelvic ligaments }\end{array}$ & $\begin{array}{l}\text { The tail is raised for longer than 1 min without any urination or defecation } \\
\text { Raised tail }\end{array}$ \\
$\begin{array}{l}\text { Viscous mucus mixed with blood appearing outside the vulva } \\
\text { Abdominal contractions }\end{array}$ & $\begin{array}{l}\text { Standing, lying on side, or partially lying on side and the abdominal muscles contract and release in a } \\
\text { rhythmic motion }\end{array}$ \\
Visible amniotic sac & The unbroken amniotic sac appears outside the vulva \\
Visible calf legs & The calf's feet and possibly part of the legs appear outside the vulva \\
\hline
\end{tabular}

$0.76)$, or length of stage II labor $(P=0.25)$. Further, no interactions were noted between pen type and movement category (see below for a description of these categories) for any variable. Thus, the pen treatment was not included in the final analysis.

In both the group and maternity pens, cows were fed a prepartum TMR ad libitum containing a dietary forage:concentrate ratio of 79:21 on a DM basis. Diets were balanced for dietary cation-anion difference; however, this was not subjected to verification through nutritional analysis. After calving, cows were fed a postpartum TMR ad libitum with a 60:40 forage to concentrate ratio on a DM basis. Feed was allocated twice daily at 1000 and $1700 \mathrm{~h}$ and fresh straw was provided at $1000 \mathrm{~h}$. After calving, cows were milked twice daily at 0600 and $1800 \mathrm{~h}$ using a manual milking machine. Water was available ad libitum in the group and maternity pens via water bowls.

\section{Experimental Design and Inclusion Criteria}

Before entering the group pen, cows within block were assigned to 1 of 2 treatments. Within parity (first, second, or later) cows were randomly assigned to treatment: (1) moved to a maternity pen $3 \mathrm{~d}$ before expected calving date, or (2) moved to a maternity pen when signs of calving were present. Before the experiment, training on the signs of calving (Table 1) was provided to all farm staff. For a week before the first cow of the experiment was due, the farm staff, farm manager, and experimenters monitored cows close to calving together, and discussed each sign of calving to reach a consensus about each definition. Cows assigned to treatment 2 were monitored for signs of calving 7 times daily (0500, 0800, 1000, 1300, 1500, 1900, and 2200 h). During each check farm staff first visually inspected cows from a distance for signs of abdominal contractions, raised tail, or suddenly enlarged, tense udder. Farm staff then entered the pen and physically inspected (i.e., palpation of the udder and pelvic ligaments) each cow while she was in a standing position. Farm staff recorded any signs they saw or felt on the cow and looked at previous records during each check. Farm staff moved cows to a maternity pen if one or more of the signs on Table 1 were noted. Calving signs and time of moving were recorded for each cow. After calving, cows were kept in the maternity pen with their calf for $3 \mathrm{~d}$ before being moved to the milking herd.

Cows were not included in the study if they calved in the group pen $(\mathrm{n}=10)$, were in the individual pen for more than $5 \mathrm{~d}(\mathrm{n}=10)$, had a difficult calving or twins $(\mathrm{n}=7)$, or were subjected to disturbing management practices (e.g., delivery of fresh bedding) by the farm staff during stage II labor $(\mathrm{n}=3)$.

The remaining 49 cows were then categorized by the stage of labor they were in when they were moved from the group pen to the maternity pen. To do this, we used (1) the time relative to calving when the cow was moved (collected retrospectively from video), and (2) the sign(s) used by the farm staff to move each cow (Table 2). Although most cows showed more than one sign of calving when they were moved (e.g., visible sac and raised tail), final category assignment was determined using the latest sign. For example, in the case where a cow was identified as having both a raised tail and a visible sac, the presence of the sac normally occurs after the raised tail and thus the cow was placed in the stage II category. The order of signs listed in Table 2 reflects our expectation as to the order of the signs relative to calving.

Sixteen cows were moved before any signs of labor, or showed signs of approaching labor (relaxed pelvic ligaments), and were moved $>24 \mathrm{~h}$ before calving ("before labor"). Seven cows were moved when signs of the second stage of labor were obvious (amniotic sac or calf legs were visible outside the vulva; "stage II"). The remaining 28 cows were moved just before or during the first stage of labor. We separated these cows into 2 categories: (1) those moved between 2 and $24 \mathrm{~h}$ before labor with a raised tail, relaxed pelvic ligaments, or suddenly enlarged, tense udder ("early stage I"; $\mathrm{n}=$ 17); and (2) those moved between 1 and about $4 \mathrm{~h}$ before calving with viscous, bloody mucus on the outside of the vulva or the first signs of abdominal contractions ("late stage I"; $\mathrm{n}=9$ ). The first category we called "early stage I," although relaxed pelvic ligaments and 
Table 2. The signs of calving used to move cows from a group pen to an individual maternity pen for each movement category, and a description of when cows calved relative to these signs

\begin{tabular}{|c|c|c|c|c|c|}
\hline \multirow{2}{*}{$\begin{array}{l}\text { Sign of calving for } \\
\text { each category }\end{array}$} & \multirow{2}{*}{$\begin{array}{l}\text { Number } \\
\text { of cows }\end{array}$} & \multicolumn{4}{|c|}{ Time spent in maternity pen $(\mathrm{h})$} \\
\hline & & Median & Mean & Minimum & Maximum \\
\hline \multicolumn{6}{|l|}{ Before labor } \\
\hline No signs & 16 & 68.2 & 74.9 & 37.2 & 117.9 \\
\hline \multicolumn{6}{|l|}{ Early stage I } \\
\hline Tense and enlarged udder & 4 & 10.5 & 10.0 & 3.6 & 15.2 \\
\hline Relaxed pelvic ligaments & 8 & 10.8 & 12.4 & 4.4 & 20.5 \\
\hline Raised tail & 5 & 12.5 & 10.5 & 2.7 & 19.3 \\
\hline \multicolumn{6}{|l|}{ Late stage I } \\
\hline Viscous mucus with blood & 7 & 2.8 & 2.6 & 1.3 & 4.1 \\
\hline Abdominal contractions & 2 & 1.7 & 1.7 & 1.4 & 2.1 \\
\hline \multicolumn{6}{|l|}{ Stage II } \\
\hline Visible amniotic sac & 4 & 0.6 & 0.5 & 0.1 & 0.8 \\
\hline Visible calf legs & 3 & 0.3 & 0.4 & 0.3 & 0.6 \\
\hline
\end{tabular}

suddenly enlarged udders may occur before labor, or during the first and second stage of labor (Noakes et al, 2001). We are confident that cows in this category were not in the second stage of labor, as this stage is recognizable by landmarks such as abdominal contractions and the amniotic sac becoming visible. However, we could not be certain that these cows were not transitioning into the first stage of labor, or were not yet at this stage, as the start of stage I is detectable only by palpation of the cervix. We called the second group "late stage I"; although these cows were likely transitioning between the first and second stage of labor, as abdominal contractions are considered a first sign of the second stage and viscous, bloody mucus is pushed through the vulva as the calf begins to move through the cervix.

All cows moved during stage II $(\mathrm{n}=7)$ calved within $1 \mathrm{~h}$ of being moved, which prevented any meaningful behavioral data from being collected from the maternity pens. Thus, these cows will not be included in the analysis.

\section{Behavior and BW Measurements}

A digital video camera was fixed above the group pen (TVCCD-460 fitted with a wide-angle lens, MO-
NACOR, Korea) and each of the individual maternity pens (TVCCD-140IR, MONACOR). Video was used by one trained observer to record the detailed behavior of each cow beginning $4 \mathrm{~h}$ before calving; table 3 shows the ethogram of behaviors and postures collected for each cow. The length of the second stage of labor was estimated by subtracting the time that the first abdominal contractions were recorded from the time of calf delivery. Abdominal contractions are one of the first signs of the second stage of labor (Noakes et al, 2001), and are easier to detect with video compared with other signs, such as appearance of the amniotic sac (e.g., if the posterior of the cow was facing away from the camera when the sac became visible outside the vulva). In the case of 2 cows classified as late stage I, the onset of abdominal contractions was observed when they were in the group pen; this record was used as the start time for abdominal contractions.

To collect meaningful behavioral data, we only included cows that were in the maternity pen for more than 1 $\mathrm{h}$ before calving. Lying time, number of times the cow changed from standing to lying (i.e., lying bouts), lying bout duration (lying time divided by the number of lying bouts), and the length of abdominal contractions were summarized for the $1 \mathrm{~h}$ before calving. During the trial we noticed that other cows in the group pen were

Table 3. Ethogram of cow postures, behaviors, and calving events recorded in the individual maternity pens $4 \mathrm{~h}$ before calving

\begin{tabular}{|c|c|c|}
\hline Variable & Level & Definition \\
\hline Lying & Posture & Lying on sternum or side, head may be rested or raised \\
\hline Attention from other cows & Group behavior & $\begin{array}{l}\text { A cow in the group pen puts any part of its head over the bars of the individual } \\
\text { maternity pen where the focal cow is housed for at least } 1 \text { min }\end{array}$ \\
\hline Start of abdominal contractions & Calving event & $\begin{array}{l}\text { First time cow is lying on side, or partially on side, and the abdominal muscles } \\
\text { contract and release in a rhythmic motion }\end{array}$ \\
\hline
\end{tabular}


approaching the cows moved during late stage I, even after they were moved into the individual pen. Thus, we also monitored the behavior of cows in the group pen during the $1 \mathrm{~h}$ before calving. Newborn calves were removed from the pen and weighed using a scale (model 4301, Danvaegt, Denmark) within 12 h after birth.

\section{Blood Samples and Haptoglobin Measurements}

A blood sample was taken from the jugular vein (vena jugularis) at $0800 \mathrm{~h}$ from a sub-sample of 23 cows 3 to $27 \mathrm{~h}$ after they had calved for analysis of haptoglobin, an indicator of systemic inflammation typically present during labor, and highest in cows with uterine disease (Huzzey et al., 2009). Although this seems to be a large variation in sampling time, evidence exists of a protracted response of bovine haptoglobin (e.g., lasting from 24 to $96 \mathrm{~h}$ after LPS injection; Jacobsen et al., 2004). Haptoglobin was measured using a sandwich ELISA originally developed by Godson et al. (1996), as described by Heegaard et al. (2000), and having a detection limit of $7.8 \mu \mathrm{g} / \mathrm{mL}$. Briefly, all samples were run in 3 dilutions together with a dilution row of calibrated bovine serum as standard, calculating the haptoglobin concentrations in the samples by interpolation using a fitted standard curve (Godson et al., 1996).

As our categorization of cows was done retrospectively, we were not able to balance these samples for movement categories (late stage $\mathrm{I}: \mathrm{n}=4$; early stage $\mathrm{I}$ : $\mathrm{n}=11$; before labor: $\mathrm{n}=8$ ).

\section{Statistical Analysis}

All statistical analyses were performed with SAS software (version 9.2; SAS Institute Inc., Cary, NC) using the cow as the experimental unit. Data were scanned for normality, and residual plots were created to determine outliers using the UNIVARIATE and GLM procedures. One extreme outlier was found in the haptoglobin data and was removed. An ANOVA (PROC GLM) was used to determine the effect of moving cows at different stages of labor on the length of the second stage of labor, the duration of abdominal contractions, lying time, lying bouts, and lying bout duration recorded in the $1 \mathrm{~h}$ before calving. The initial model included block, but this had no effect on any variable and was removed. The final model included parity and calf weight as covariates and movement category (late stage I, early stage I, or before labor) as a main effect. The PDIFF statement was used to compare the LSM of each movement category.

As we had insufficient power to test the effect of movement category on haptoglobin, we instead tested an alternative hypothesis that prolonged labor might
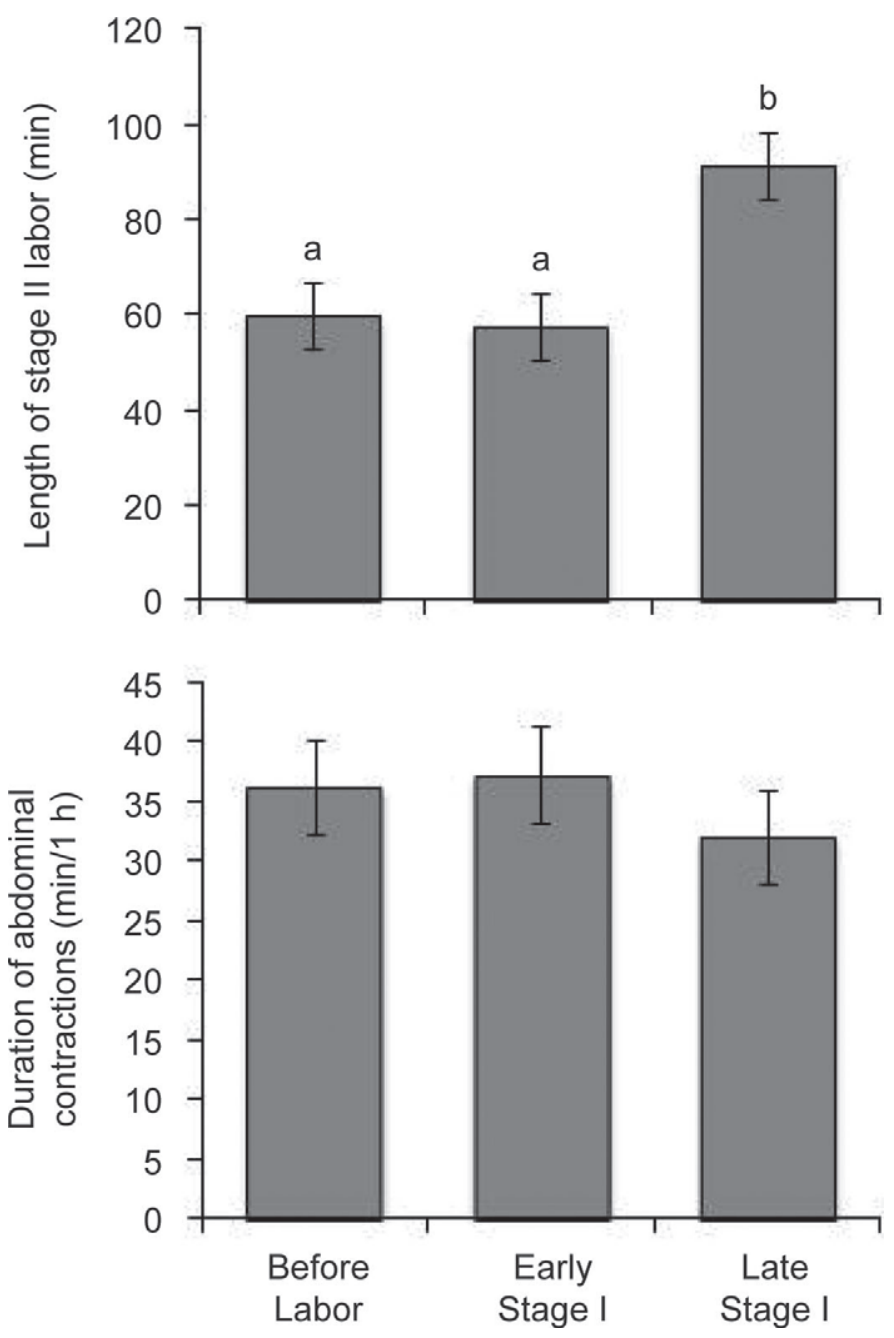

Figure 1. Least squares means and SE of length of stage II labor and duration of abdominal contractions in the $1 \mathrm{~h}$ before calving for cows moved from a group to an individual maternity pen before labor $(\mathrm{n}=16$; no signs $)$, during early stage I labor $(\mathrm{n}=17$; signs of raised tail, relaxed pelvic ligaments, or enlarged, tense udder), or during late stage I labor ( $\mathrm{n}=9$; signs of viscous, bloody mucus or contractions). ${ }_{\mathrm{a}, \mathrm{b}}$ Bars with different letters are significantly different at $P<0.05$.

result in higher systemic inflammation. We tested the relationship between length of stage II labor and haptoglobin using a model that included hour of sampling relative to calving and length of stage II labor in that order.

To determine the effect of movement category on attention from group-mates, data were transformed into binomial data $(0=$ no attention, $1=$ at least one cow had her head over the pen for at least $1 \mathrm{~min})$. A logistic model (PROC LOGISTIC) was used with category as the only explanatory variable; late stage I was compared with the 2 other categories using a contrast statement.

Prior to the experiment, we conducted a power analysis assuming just 2 treatments (moved before calving and moved during the first stage of labor) and 

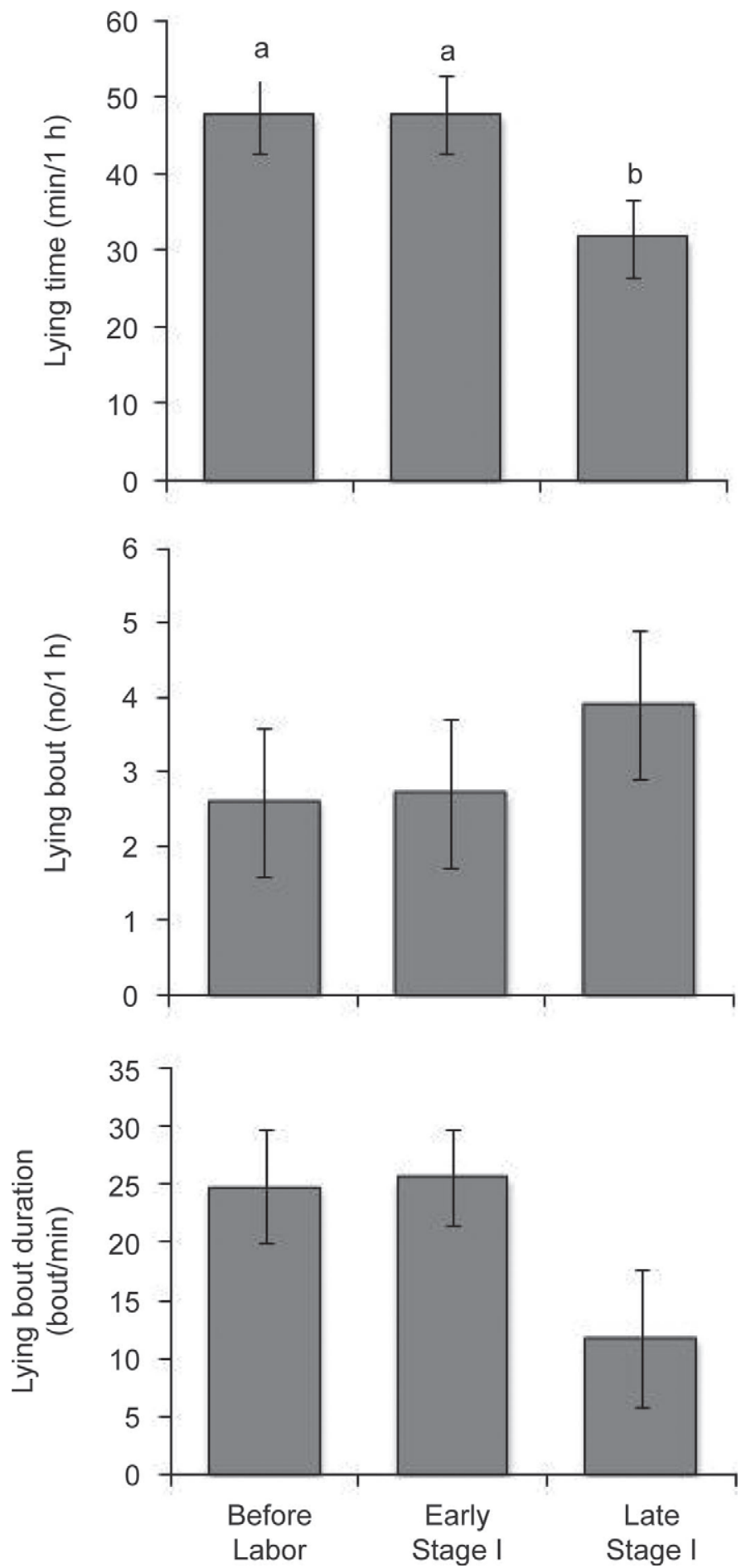

Figure 2. Least squares means and SE of time spent lying, number of lying bouts, and lying bout duration during the $1 \mathrm{~h}$ before calving for cows moved from a group to an individual maternity pen before labor ( $\mathrm{n}=16$; no signs), during early stage I labor $(\mathrm{n}=17$; signs of raised tail, relaxed pelvic ligaments, or enlarged, tense udder), or during late stage I labor $(\mathrm{n}=9$; signs of viscous, bloody mucus or contractions). ${ }^{\mathrm{a}, \mathrm{b}}$ Bars with different letters are significantly different at $P<0.05$. determined that we needed approximately 24 cows per treatment. However, our final data set has 3 categories that reduced our sample size most notably for cows moved during the first stage of labor (now "early" and "late"). Given this change in sample size, we conducted a post hoc power analysis for all variables measured (using the PROC POWER procedure of SAS software for a one-way unbalanced ANOVA). Length of stage II labor and lying time had high power (93.7 and $78.3 \%$, respectively), lying bout duration and lying bouts had moderate power (67.4 and $54.6 \%$, respectively), and duration of abdominal contractions had very low power $(11.5 \%)$. $P$-values are considered significant at $<0.05$ and tendencies at $<0.10$.

\section{RESULTS}

\section{Length of Stage II Labor and Abdominal Contractions}

Figure 1 shows the effect of movement category on length of stage II labor and length of abdominal contractions in the $1 \mathrm{~h}$ before calving. After controlling for calf weight and parity, cows that were moved to an individual pen during late stage I had the longest stage II labor $(P<0.001)$, but did not differ in the duration of abdominal contractions in the hour before calving $(P=0.52)$.

\section{Behavior in the Hour Before Calving}

Figure 2 shows the effect of movement category on lying time, the number of lying bouts, and the length of lying bout duration in the $1 \mathrm{~h}$ before calving. Cows that were moved to an individual pen during late stage I spent the least time lying $(P=0.002)$, but did not differ in the number of lying bouts $(P=0.20)$. A tendency for shorter lying bout in cows moved during late stage I $(P=0.09)$ was noted.

Cows that were moved during late stage I tended to have a higher likelihood of receiving attention from group cows compared with the other categories $(P=$ 0.06). Six of 9 cows in late stage I, 5 of 17 cows in early stage I, and 4 of 16 cows moved before labor had attention from cows in the group pen.

\section{Haptoglobin}

After controlling for time of sampling, haptoglobin moderately increased as length of the second stage of labor increased $\left(\mathrm{R}^{2}=0.42 ; P=0.01\right)$.

\section{DISCUSSION}

The aims of this study were to determine if moving cows from a group pen to an individual maternity pen 
at different stages of labor affected calving behavior or the progression of labor. Cows moved during the late part of stage I labor (or perhaps transitioning from the first to the second stage) showing viscous, bloody mucus outside the vulva or abdominal contractions had the longest second stage of labor, spent the least time lying, and received slightly more attention from other cows during labor.

Most interesting was that the total duration of the second stage of labor was about 30 min longer for cows moved during the late part of the first stage of labor, compared with those moved during the earlier part of the first stage and those moved before labor (91 vs. 58 and $60 \mathrm{~min}$, respectively). Two recent studies reported estimates of normal length of the second stage of labor in cows with unassisted calvings; Barrier et al. (2012) estimated the median time from signs of calf feet to calving to be $54.7 \mathrm{~min}$, and Schuenemann et al. (2011) estimated the mean time from signs of amniotic sac to calving to be $45.1 \mathrm{~min}$. The time from first abdominal contractions to calving recorded in our study for cows moved before labor and during early stage I labor is slightly longer than these estimates, presumably because some time exists between the first abdominal contractions and the appearance of the amniotic sac or calf feet. It is, however, somewhat concerning that the cows in our experiment that were moved during late stage I labor experienced much longer stage II labors compared with cows having unassisted calvings in both of these studies.

Because of the small sample size, we were unable to detect any potential effect of prolonged stage II labor on the health of the dam or the calf. In a study using a much larger sample size, Gundelach et al. (2009) found that cows with stage II labors $>120$ min had a higher risk of stillbirth compared with those with shorter stage II labor. We did not record any cases of stillbirths in this study, likely because with our small sample size we did not encounter any cows with stage II labor as long as those in Gundelach et al. (2009). Prolonged stage II labor is also associated with dystocia (Schuenemann et al., 2011; Barrier et al., 2012).

The reasons for prolonged stage II labor in latemoved cows remain unclear. At this stage, the calf is in its birthing position (i.e., front legs and head facing the cervix) and is beginning to move into an expanding birth canal (Noakes et al, 2001). Moving a cow into a novel environment during this sensitive period may cause deviations from the normal sequence of calving behaviors or physiological changes that should occur. Indeed, normal calving behavior was disturbed in cows moved during late stage I labor. These cows spent half as much time lying in the hour before calving compared with both of the other categories. Previous work has reported that when cows calved without assistance they became recumbent at the start of abdominal contractions and remained in this position until birth (Schuenemann et al., 2011). Thus, the low lying time recorded in the cows moved during late stage I labor is likely a deviation from normal calving behavior. Any practice that increases prepartum standing time should be avoided, as it may also increase the risk of lameness later in lactation or may be an early predictor of lameness (Proudfoot et al., 2010).

The lower lying time of cows moved during late stage I may be related to the cow responding to the novel and slightly more restrictive environment of the maternity pen. Preparturient sows housed in restrictive farrowing crates that do not allow for the expression of normal preparturient behaviors will increase the number of postural changes and reduce standing time in the hours before farrowing (Jarvis et al., 2001). In our case, cows moved to a maternity pen just before calving (late stage I) did not differ in postural changes in the hour before calving compared with the other categories, although the power may have been too low to detect differences because of our low sample size. Instead, they had slightly shorter lying bouts and were more reluctant to become recumbent, perhaps spending more time exploring their new pen to ensure that it is a safe place to give birth.

The tendency for cows moved during late stage I to draw more attention from cows within the group is interesting. These cows were moved within $4 \mathrm{~h}$ of calving, so perhaps the changes in their behavior or the odor of amniotic fluid while they were in the group pen may be appealing to other cows in the pen. Both preparturient cows and ewes are attracted to newborns (Edwards, 1983), as well as to amniotic fluid alone before parturition in cows (Pinheiro Machado et al., 1997) and during parturition in ewes (Arnould et al., 1991). Given the small number of cows used in this study, we strongly encourage future work in this area.

Although we did not have sufficient power to test the effect of movement category on early postpartum haptoglobin, we provided some evidence that cows with longer stage II labor have higher inflammation after calving. Haptoglobin, a marker of systemic inflammation, is normally elevated just after calving and declines within the first 6 to $9 \mathrm{~d}$ of calving in healthy cows (Huzzey et al., 2009). Despite the variation in the timing of the blood samples (blood samples were taken between 3 and $27 \mathrm{~h}$ after calving), we found that cows experiencing a longer second stage of labor had higher levels of serum haptoglobin postcalving. High haptoglobin during this period may be a sign of stress or tissue damage during calving, and may also predict later uterine disease (Huzzey et al., 2009). Future research, 
using larger sample sizes and more precisely timed blood samples, is encouraged to determine the effect of prolonged stage II labor on uterine health outcomes.

Only one other study has examined the effect of moving cows from a group to a maternity pen on health outcomes (stillbirths; Carrier et al., 2006). Similar to our findings, those authors found a detrimental effect of moving cows during the late part of the first stage of labor (with signs of viscous mucus, with or without blood), although these cows were compared with those moved during the second stage, which we were unable to measure. Specifically, they found a 2.5 -fold increase in stillbirths in cows moved during the late part of the first stage of labor. Based on their findings, Carrier et al. (2006) recommended moving cows with signs of the second stage of labor. However, moving cows during the second stage of labor, or "just in time," presents its own challenges. Waiting to move cows at this late stage will certainly increase the number of cows that calve in the group pen (or nonmaternity pens). In our case, 10 of 79 cows calved in the group pen, despite farm staff checking cows 7 times per day for signs of calving. Little research has been done on the effect of calving cows in groups. In one study, Edwards (1983) discovered that cows housed in groups spent less time licking their calves compared with cows housed individually. This reduction in licking time was likely due to other cows in the group licking the newborn calves (Edwards, 1983). Some evidence also exists that cows prefer seclusion to calve; cows housed in semi-natural environments (Lidfors et al., 1994) distance themselves from herd mates in the few hours before calving.

In the case where producers elect to move cows to an individual maternity pen just before calving, an optimal time for this movement to take place might exist. Although our study was unable to determine when the best time to move is, it is clear that a sensitive period occurs near the end of the first stage of labor - or the transition between stage I and II-where moving a cow would disrupt normal calving behavior and the progress of labor. We also note that we found no differences between cows moved before signs of labor (up to $5 \mathrm{~d}$ before calving) and those moved during early signs of labor.

\section{CONCLUSIONS}

When cows were moved from a group to an individual maternity pen during the late part of stage I or early part of stage II labor (i.e., signs of contractions or viscous, bloody mucus), their behavior was disturbed and the length of the second stage of labor prolonged. These cows also spent less time lying in the hour before calving and tended to get more attention from group mates.

\section{ACKNOWLEDGMENTS}

The authors gratefully acknowledge the barn staff of the cattle facility at Aarhus University's Research Centre in Foulum. Thanks to John Misa Obidah and Erik Luc Decker (both at Aarhus University) for assisting with data collection and handling. K. L. Proudfoot was funded in part by The Aarhus University Research Foundation as a visiting $\mathrm{PhD}$ student. The research was funded by the Danish Ministry of Food, Agriculture and Fisheries.

\section{REFERENCES}

Arnould, C., V. Piketty, and F. Lévy. 1991. Behaviour of ewes at parturition toward amniotic fluids from sheep, cows and goats. Appl. Anim. Behav. Sci. 32:191-196.

Barrier, A. C., M. J. Haskell, A. I. Macrae, and C. M. Dwyer. 2012. Parturition progress and behaviors in dairy cows with calving difficulty. Appl. Anim. Behav. Sci. http://dx.doi.org/10.1016/j. applanim.2012.03.003.

Canadian Council on Animal Care. 1993. Guide to the Care and Use of Experimental Animals. Vol. 1. E. D. Olfert, B. M. Cross, and A. A. McWilliam, ed. CCAC, Ottawa, Ontario, Canada.

Carrier, J., S. Godden, J. Fetrow, S. Stewart, and P. Rapnicki. 2006. Predictors of stillbirth for cows moved to calving pens when calving is imminent. Page 158-159 in Proc. 39th Ann. Amer. Assn. Bov. Pract., Auburn, AL.

Edwards, S. A. 1983. The behaviour of dairy cows and their newborn calves in individual or group housing. Appl. Anim. Ethol. 10:191-198.

Godson, D. L., M. Campos, S. K. Attah-Poku, M. J. Redmond, D. M. Cordeiro, M. S. Sethi, R. J. Harland, and L. A. Babiuk. 1996. Serum haptoglobin as an indicator of the acute phase response in bovine respiratory disease. Vet. Immunol. Immunopathol. 51:277-292.

Gundelach, Y., K. Essmeyer, M. Teltscher, and M. Hoedemaker. 2009. Risk factors for perinatal mortality in dairy cattle: Cow and foetal factors, calving process. Theriogenology 71:901-909.

Heegaard, P. M. H., D. L. Godson, M. J. M. Toussaint, K. Tjørnehøj, L. E. Larsen, B. Viuff, and L. Rønsholt. 2000. The acute phase response of haptoglobin and serum amyloid A (SAA) in cattle undergoing experimental infection with bovine respiratory syncytial virus. Vet. Immunol. Immunopathol. 77:151-159.

Huzzey, J. M., T. Duffield, S. LeBlanc, D. Veira, D. Weary, and M. von Keyserlingk. 2009. Short communication: Haptoglobin as an early indicator of metritis. J. Dairy Sci. 92:621-625.

Huzzey, J. M., M. A. G. von Keyserlingk, and D. M. Weary. 2005. Changes in feeding, drinking, and standing behavior of dairy cows during the transition period. J. Dairy Sci. 88:2454-2461.

Ingvartsen, K. L. 2006. Feeding- and management-related diseases in the transition cow: Physiological adaptations around calving and strategies to reduce feeding-related diseases. Anim. Feed Sci. Technol. 126:175-213.

Jackson, P. G. G. 2004. Normal birth. Pages 1-12 in Handbook of Veterinary Obstetrics. 2nd ed. Saunders, Philadelphia, PA.

Jacobsen, S., P. H. Andersen, T. Toelboel, and P. M. H. Heegaard. 2004. Dose dependency and individual variability of the lipopolysaccharide-induced bovine acute phase protein response. J. Dairy Sci. 87:3330-3339.

Jarvis, S., B. J. Van der Vegt, A. B. Lawrence, K. A. McLean, L. A. Deans, J. Chirnside, and S. K. Calverta. 2001. The effect of parity and environmental restriction on behavioural and physiological responses of pre-parturient pigs. Appl. Anim. Behav. Sci. $71: 203-216$.

Jensen, M. B. 2012. Behaviour around the time of calving in dairy cows. Appl. Anim. Behav. Sci. 139:195-202. 
Lidfors, L. M., D. Moran, J. Jung, P. Jensen, and H. Castren. 1994. Behaviour at calving and choice of calving place in cattle kept in different environments. Appl. Anim. Behav. Sci. 42:11-28.

Mainau, E., and X. Manteca. 2011. Pain and discomfort caused by parturition in cows and sows. Appl. Anim. Behav. Sci. 135:241-251.

Miedema, H. M., M. S. Cockram, C. M. Dwyer, and A. I. Macrae 2011. Changes in the behaviour of dairy cows during the $24 \mathrm{~h}$ before normal calving compared with behaviour during late pregnancy. Appl. Anim. Behav. Sci. 131:8-14.

Noakes, D. E., T. J. Parkinson, G. C. W. England, and G. H. Arthur. 2001. Parturition and the care of parturient animals. Page 155-187 in Arthur's Veterinary Reproduction and Obstetrics. 8th ed. Saunders, Philadelphia, PA.

Overton, T., and M. Waldron. 2004. Nutritional management of transition dairy cows: Strategies to optimize metabolic health. J. Dairy Sci. 87(E. Suppl.):E105-E119.

Pedersen, L. J., and T. Jensen. 2008. Effects of late introduction to two farrowing environments on the progress of farrowing and maternal behavior. J. Anim. Sci. 86:2730-2737.
Pinheiro Machado, F. L., J. Hurnik, and G. King. 1997. Timing of the attraction towards the placenta and amniotic fluid by the parturient cow. Appl. Anim. Behav. Sci. 53:183-192.

Proudfoot, K. L., M. B. Jensen, and M. A. G. von Keyserlingk. 2012. Indoor-housed dairy cows seek isolation from herd mates at calving. Nordic ISAE, Skara, Sweden (Abstr). http://www.appliedethology.org/download216.html.

Proudfoot, K. L., D. M. Weary, and M. A. G. von Keyserlingk. 2010. Behavior during transition differs for cows diagnosed with claw horn lesions in mid lactation. J. Dairy Sci. 93:3970-3978.

Rushen, J., A. Boissy, E. M. Terlouw, and A. M. de Passillé. 1999. Opioid peptides and behavioral and physiological responses of dairy cows to social isolation in unfamiliar surroundings. J. Anim. Sci $77: 2918-2924$

Schuenemann, G. M., I. Nieto, S. Bas, K. Galvão, and J. Workman. 2011. Assessment of calving progress and reference times for obstetric intervention during dystocia in Holstein dairy cows. J. Dairy Sci. 94:5494-5501. 